\title{
$\mathrm{COB}, \mathrm{COH}$ Package LED Module 열 해석 시뮬레이션
}

\author{
최금연 ${ }^{1^{*}}$, 어익수 $^{2}$ \\ ${ }^{1}$ 호남대학교 전기공학과
}

\section{COB, COH Package LED Module Thermal Analysis Simulation}

\author{
Keum-Yeon $\mathrm{Choi}^{{ }^{1^{*}}}$ and Ik-Soo Eo $^{2}$ \\ ${ }^{1}$ Dept. of Electrical Engineering, Honam University
}

\begin{abstract}
요 약 본 논문에서는 열 해석 시뮬레이션 프로그램인 COMSOL Multiphysics를 활용하여, LED Module의 제작 시, 가장 선호되는 패키지 종류인 $\mathrm{COB}$ Type과 보드를 생략한 $\mathrm{COH}$ Type의 열 해석 시뮬레이션을 진행한다. LED Module의 시뮬레이션 결과 방열판을 통과하는 위치에 따라 $\mathrm{COB}$ Type은 Max. 약 $78^{\circ} \mathrm{C} \sim \operatorname{Min}$. 약 $62^{\circ} \mathrm{C}$, COH Type 은 Max. 약 $88^{\circ} \mathrm{C} \sim \operatorname{Min}$. 약 $67^{\circ} \mathrm{C}$ 에서 온도가 안정이 됨을 확인하였다. $\mathrm{COB}$ Type과 비교하여 Max. 온도는 약 $10^{\circ} \mathrm{C}$ 차이가 나지만, Min. 온도에서 약 $5^{\circ}$ C정도로 격차가 감소함을 확인하였으며, LED Point 온도특성곡선을 확인 한 결 과 COB Type은 Max. 약 $100^{\circ} \mathrm{C} \sim \operatorname{Min}$. 약 $77^{\circ} \mathrm{C}$, COH Type은 Max. 약 $100^{\circ} \mathrm{C} \sim \operatorname{Min}$. 약 $86^{\circ} \mathrm{C}$ 온도가 안정이 됨을 확인하였으며, $\mathrm{COB}$ Type에 비해 $\mathrm{COH}$ Type이 약 $10^{\circ} \mathrm{C}$ 온도가 높게 측정되었다.
\end{abstract}

\begin{abstract}
In this paper, thermal analysis simulation program by taking advantage of COMSOL Multiphysics, LED Module for the production of the most preferred package type, omitting the COH Type COB Type and board simulation of the thermal analysis is in progress. LED Module that passes through the Heat-sink of the simulation results, depending on the location of the COB Type Max. Approximately $78^{\circ} \mathrm{C} \sim$ Min. Approximately $62^{\circ} \mathrm{C}$, $\mathrm{COH}$ Type the Max. Approximately $88^{\circ} \mathrm{C} \sim$ Min. Approximately $67^{\circ} \mathrm{C}$ has been confirmed that the temperature stability. Compared with $\mathrm{COB}$ Type Max. Although temperature difference is about $10{ }^{\circ} \mathrm{C}$, Min. At a temperature of about $5{ }^{\circ} \mathrm{C}$ confirmed to be enough to reduce the gap, LED Point confirming the results of the temperature curves for $\mathrm{COB}$ Type Max. Approximately $100{ }^{\circ} \mathrm{C} \sim$ Min. Approximately $77{ }^{\circ} \mathrm{C}$, $\mathrm{COH}$ Type the Max. Approximately $100{ }^{\circ} \mathrm{C} \sim$ Min. Approximately $86{ }^{\circ} \mathrm{C}$ temperature stability was confirmed that, $\mathrm{COB}$ Type $\mathrm{COH}$ Type, compared to approximately $10{ }^{\circ} \mathrm{C}$ temperature was higher.
\end{abstract}

Key Words : LED, COB, $\mathrm{COH}$

\section{1. 서론}

고출력 LED(Light Emitting Diode)의 특성 및 신뢰성 은 $\mathrm{LED}$ 의 접합에서 발생하는 열에 의해 크게 좌우한다. 일반적인 고출력 $\mathrm{LED}$ 에서는 약 $1 \mathrm{~W} / \mathrm{mm}^{2}$ 의 열을 발생시 킨다. LED에서 발생하는 열은 패키지내의 열팽창계수가 서로 다르기 때문에 최대 정격이상의 높은 온도에 노출 시키거나 열 순환을 반복하면 각기 다른 유형의 치명적 고장을 초래할 수 있다[1]. LED Module 개발을 위해 무 엇보다도 열문제가 야기된다. 열이 높아지면 모듈의 수명 이 감소되며, $\mathrm{LED}$ 용 기판에 필수 불가결한 특성은 방열
성이 높아야 한다는 점이고, 메탈 베이스 기판의 구성 재 료로서 메틸 베이스 판으로는 알루미늄과 동을, 그리고 절연 층에는 열전도성이 높은 무기 필터를 충전한 에폭 시 계 수지로 사용되는 경우가 많아졌다. 특히 알루미늄 베이스 기판은 알루미늄의 특성으로 높은 열전도성과 경 량성 등을 살린 고밀도 실장기판이며, 에어컨의 인버터용 기판, 통신용 전원용 기판과 산업용도면에서의 사용실적 이 높다는 점에서도 파워 $\mathrm{LED}$ 용 기판의 열 설계에 가장 적합하다고 본다[2].

LED 패키지 형태는 Dome Type과 Cavity Type으로 나누어지며, 접합 방식 및 쓰임에 따라 다양한 패키지 종

"교신저자: 최금연(mysea518@nate.com)

접수일 11년 09월 29일수정일 (1차 11년 10월 28일, 2차 11년 11월 09일)

게재확정일 11 년 11 월 10 일 
류가 있다. 이중 가장 선호되는 패키지 종류로는 SMD (Surface Mount Devices)Type과 COB(Chip on Board) Type을 들 수 있다. 표면실장소자라 불리는 SMD Type은 $\mathrm{PCB}$ 기판에 구멍 없이 패턴에 바로 반도체 소자를 붙이 는 방식이다. 대부분 $\mathrm{PCB}$ 에 다량의 LED 패키지를 실장 을 할 경우에 선호된다. $\mathrm{COB}$ Type은 와이어 본딩이 직 접 되어있는 형태로 패키지 저항이 $10^{\circ} \mathrm{C} / \mathrm{W}$ 이내이므로 방열성능이 우수하지만 패키지 하나가 고장이 나면 조명 기기 전체가 고장이 나는 단점이 있다. WLP(Wafer Level Package)가 존재하지만 고가의 장비를 사용, 실리콘 기판 을 가공하여 실장 할 경우 $70 \%$ 밖에 실장이 되지 않기 때 문에 선호도가 낮다. 이밖에도 Mirror Type, Mold Type, Can Type 등이 존재한다[3]. 또한 기존의 패키지와 달리 방열판 위에 Chip을 본딩하는 $\mathrm{COH}$ (Chip on Heat-sink) Type이 있으며, $\mathrm{COH}$ 는 보드를 생략한 패키지로서 $\mathrm{COB}$ 에 비해 제작 원가가 저렴하지만 좀 더 기술적 보완이 필 요하다.

산업체의 LED Module 열 설계 시 시뮬레이션 절차를 거치지 않고 금형 및 제작하여, Module의 전원을 공급하 면, 시간의 흐름에 따라 온도계 측정을 통한 열 해석을 진행하는 경우가 있다. 실제 제작을 통한 열 측정을 하면, 개발에 따른 많은 경비가 소비된다. 하여, 본 시뮬레이션 통한 LED Module의 Modeling 및 시뮬레이션 열 해석 방 법은 산업체의 LED Module 개발 시 경비 절감의 효과를 기대할 수 있다. 시뮬레이션 과정은 LED Package 제작 도면을 $3 \mathrm{D}$ 로 구현하여, LED Point와 PCB 및 보드의 단 면의 열 발생에 의한 결과를 확인한다. 본 논문에서는 $\mathrm{COB}$ Type과 보드를 생략한 $\mathrm{COH}$ Type의 열 해석 시뮬 레이션을 진행한다. 기존의 열 설계 시뮬레이션에서는 단 면위주의 열 해석이지만, Point 지정을 통한 열 해석을 및 실험을 하여 더욱 자세한 결과 값을 얻을 수 있다.

\section{2. 본 론}

\subsection{LED Package의 방열설계 이론}

시뮬레이션과정의 기본 열 해석 지배식인 열전도는 고 체 매질을 통해 일어나는 열전달 형태로 물체 내에 온도 구배가 존재할 때 열은 고온에서 저온부로 전달된다. 미 시적 관점에서 보면 물질 내 원자나 분자의 상호작용에 의해 열이 전달되며, 즉 원자 격자의 진동과 자유전자의 이동에 의해 인접한 분자에 에너지를 전달하는 열 유동 률은 매질의 물성 값인 열전도계수 $\mathrm{k}$ 에 좌우되며, 열전도 법칙인 Fourier's Law을 적용하였으며, Fourier's Law은 수식(1)이다.

$$
\frac{\Delta Q}{\Delta t}=-k A \frac{\Delta T}{\Delta x}
$$

$\mathrm{A}$ 는 단면적, $\triangle \mathrm{T}$ 는 온도변화량, $\mathrm{x}$ 는 길이, $\mathrm{k}$ 는 열전도 도이다.

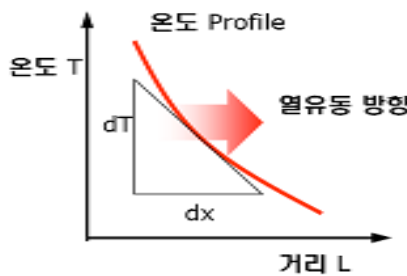

[그림 1] 온도와 거리비례곡선

[Fig. 1] Curve Proportional to the Temperature and the Distance

그림 1은 온도 변화에 따른 열 유동에 관한 그래프이 며, 온도와 거리는 반비례함을 확인할 수 있다.

$$
\begin{gathered}
Q=-k \cdot A_{C} \cdot \frac{\Delta T}{L}, \Delta T=\frac{Q \cdot L}{k \cdot A_{C}} \\
\mathrm{Q}=\text { 열 유동비 }(\mathrm{W}) \\
\mathrm{k}=\text { 열전도도 }(\mathrm{W} / \mathrm{m} \cdot \mathrm{K}) \\
A_{C}=\text { 방열판의 열 유동 면적 }\left(\mathrm{m}^{2}\right) \\
\left.\Delta T=\text { 차동온도 }{ }^{\circ} \mathrm{C}\right) \\
\mathrm{L}=\text { 방열판의 길이 }(\mathrm{m}) \\
\rho u \cdot \Delta u=\Delta \cdot\left[-p I+\eta\left(\Delta u+(\Delta u)^{T}\right)\right. \\
\quad-(2 \eta / 3)(\Delta \cdot u) I]+\rho g \\
\Delta \cdot(\rho u)=0 \quad\left(-k \Delta T+\rho C_{P} T u\right)=0
\end{gathered}
$$

수식(1-1) (1-5)는 열 해석 시뮬레이션의 열용량에 대 한 압력, 열전도, 속도벡터의 방정식을 차동속도와 대입하 였으며, 시뮬레이션의 기본 열 해석 지배식으로 $\mathrm{n}$ : 점도 $(\mathrm{kg} /(\mathrm{m} \bullet \mathrm{s})), u$ : 속도벡터 $(\mathrm{m} / \mathrm{s}), \mathrm{\rho}$ : 밀도 $\left(\mathrm{kg} / \mathrm{m}^{3}\right), \mathrm{p}$ : 압력 $(P a), \mathrm{k}$ : 열전도 $(\mathrm{W} /(\mathrm{K} ・ \mathrm{~m})), \mathrm{Cp}$ :열용량 $(\mathrm{J} /(\mathrm{kg} ・ \mathrm{~K}))$ 이 다[4]. 또한, 열발전소자에서 최대출력은 일반의 전기회 로와 같이 $\mathrm{m}-1$ 일 때, $\mathrm{rm}$ 효율은 다음 식과 같다.

$$
\begin{aligned}
& \eta=(m-1) \frac{\Delta T}{T_{h}} \frac{1}{2+4 / Z T_{h}-\Delta T /\left(2 T_{h}\right)} \\
& (R / r)_{o p t}=\sqrt{(1+Z T)}=M
\end{aligned}
$$




$$
\begin{aligned}
& P=\left(a_{p n} \Delta T-r I\right) I=R I^{2} \\
& I_{o p t}=a_{p n} \Delta T /(1+M) r \\
& \eta M a x=\frac{\Delta T}{T_{h}} \frac{M-1}{M+\left(T_{c} / T_{h}\right)}
\end{aligned}
$$

효율 $n$ 이 최대가 되는 $\mathrm{m}$ 을 구하기 위하여 $\partial \mathrm{N} \partial \mathrm{m}=\mathrm{O}$ 으로 놓고, $\mathrm{m}$ 에 대하여 풀면, 최적 저항 비는 (2-2)이며, $(\mathrm{R} / \mathrm{r})_{\mathrm{opt}}$ 를 (2-3)식에 대입하여 I에 대하여 풀면, 최적 전 류는 (2-4)이다. 또한, 이때의 최대효율 $\eta_{\mathrm{Max}}$ 는 (2-5)로 하 여, 열전소자인 $\mathrm{LED}$ (실리콘), $\mathrm{PCB}$ 와 방열판(알루미늄)의 열전도와 밀도, 열용량을 산정하였다[5].

\subsection{LED Package의 제원(COB, $\mathrm{COH})$}

표 1은 LED Module의 가로, 세로, 높이를 측정한 값 이며 $\mathrm{PCB}$ 와 방열판의 재질은 알루미늄, $\mathrm{LED}$ 의 재질은 실리콘으로 선정하였다.

[표 1] LED Module의 제원

[Table 1] Specifications of LED Module

\begin{tabular}{|c|c|c|}
\hline 구분 & $\mathrm{COB}$ & $\mathrm{COH}$ \\
\hline $\mathrm{PCB}$ (알루미늄) & $225.8 \times 30 \times 0.3 \mathrm{~mm}$ & $\bullet$ \\
\hline 방열판(알루미늄) & $240 \times 40 \times 2 \mathrm{~mm}$ & $240 \times 40 \times 2 \mathrm{~mm}$ \\
\hline $\mathrm{LED}$ (실리콘) & $1 \mathrm{~mm}$ & $1 \mathrm{~mm}$ \\
\hline
\end{tabular}

표 2는 LED Package의 열전도, 밀도, 열용량을 나타낸 Spec. 으로 동일한 조건으로 실험을 진행한다.

[표 2] LED Package Spec.

[Table 2] LED Package Spec.

\begin{tabular}{|c|c|c|}
\hline 구분 & LED & PCB, 방열판 \\
\hline 열전도 & $1.38 \mathrm{~W} /(\mathrm{m} \bullet \mathrm{k})$ & $160 \mathrm{~W} /(\mathrm{m} \bullet \mathrm{k})$ \\
\hline 밀도 & $2203 \mathrm{Kg} / \mathrm{m}^{3}$ & $2700 \mathrm{Kg} / \mathrm{m}^{3}$ \\
\hline 열용량 & $703 \mathrm{~J} /(\mathrm{kg} \bullet \mathrm{k})$ & $900 \mathrm{~J} /(\mathrm{kg} \bullet \mathrm{k})$ \\
\hline
\end{tabular}

\subsection{LED Module 시뮬레이션}
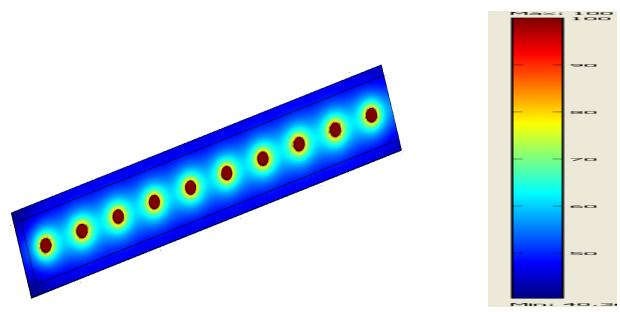

(A) COB Type
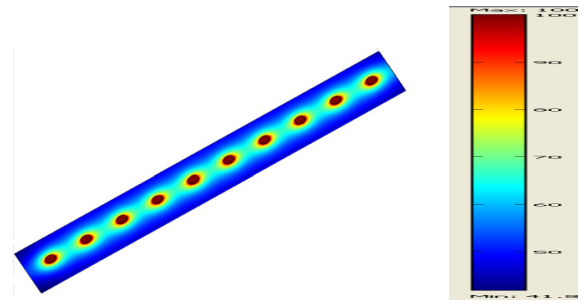

(B) $\mathrm{COH}$ Type

[그림 2] LED Module 표면 열 해석(전면)

[Fig. 2] Thermal Analysis of Surface LED Module (Front)

그림 2의 (A)는 COB Type의 평면 열 해석으로 LED 의 Max. 온도가 $100^{\circ} \mathrm{C}$ 로 가정하여 그 결과를 나타낸 그 림이다. $\mathrm{LED}$ 주변을 중심으로 열이 발산되어 $\mathrm{PCB}$ 표면에 서 약 $80^{\circ} \mathrm{C}$ 로 온도를 낮춤을 확인하였으며, $\mathrm{PCB}$ 아래 본 딩 된 방열판으로 열이 전도, 약 $65^{\circ} \mathrm{C}$ 로 감소하여, $\mathrm{LED}$ Module의 Min. 온도는 약 $40^{\circ} \mathrm{C}$ 로 확인되었다. (B)는 $\mathrm{COH}$ Type으로 $\mathrm{COB}$ Type과 같이 LED의 Max. 온도가 $100^{\circ} \mathrm{C}$ 로 가정하여 그 결과를 확인하였으며, LED 주변의 온도가 약 $90^{\circ} \mathrm{C}$ 로 $\mathrm{COB}$ Type과 달리 약 $10^{\circ} \mathrm{C}$ 가 높음을 확인하였다. 하지만 $\mathrm{PCB}$ 가 없음에도 알루미늄 방열판에 서 빠르게 열을 흡수하여 방열판 중심은 약 $65^{\circ} \mathrm{C}$ 까지 온 도가 낮아졌으며, LED Module의 Min. 온도는 약 $41{ }^{\circ} \mathrm{C}$, $\mathrm{COB}$ Type과 큰 차이가 없음을 확인하였다.

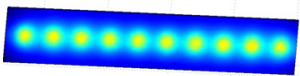

(A) COB Type

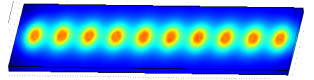

(B) $\mathrm{COH}$ Type
[그림 3] LED Module 표면 열 해석(후면)

[Fig. 3] Thermal Analysis of Surface LED Module (Back)

그림 3은 그림 2의 열 해석 결과를 추론하여, $\mathrm{PCB}$ 를 생략한 $\mathrm{COH}$ Type이 $\mathrm{COB}$ Type과 온도분포가 큰 차이 없음을 LED Module의 후면에서 확인 한 결과 $\mathrm{COH}$ Type이 COB Type에 비해 방열판에서 더 많은 열을 흡수 함을 확인 할 수 있었다.

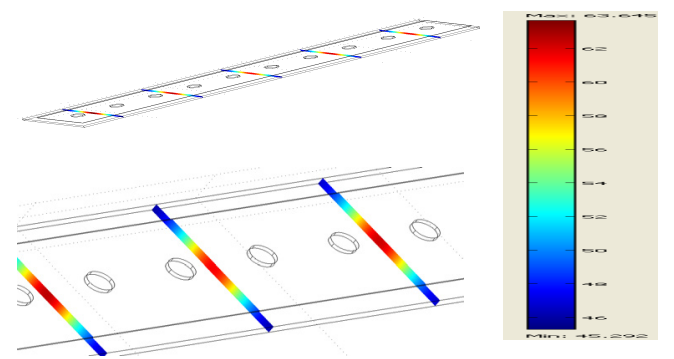

(A) COB Type 


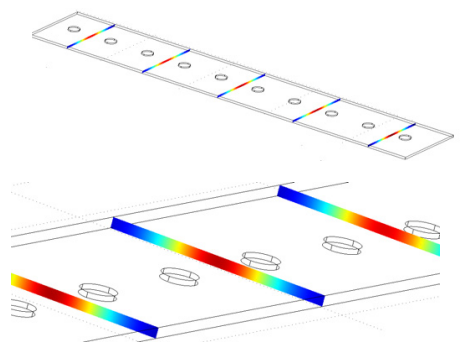

(B) $\mathrm{COH}$ Type

[그림 4] LED Module 단면 열 해석

[Fig. 4] Thermal Analysis of the Cross-section LED Module

그림 4의 (A), (B)는 LED Module의 단면 열 해석으로 LED Point 사이의 온도분포이며, (A) COB Type은 단면 Max. 온도가 약 $63^{\circ} \mathrm{C}$ 이며, Min. 온도는 약 $45^{\circ} \mathrm{C}$ 까지 온 도변화를 확인 하였다. (B) $\mathrm{COH}$ Type은 단면 Max. 온도 가 약 $68^{\circ} \mathrm{C}$ 이며, Min. 온도는 약 $47^{\circ} \mathrm{C}$ 까지 온도가 분포 하였으며, LED Point에서 보다 COH Type의 방열판에서 보다 많은 열을 흡수하여 온도 차트에 보이는 것과 같이 Max. 온도에서 Min. 온도까지 COB Type 보다 빠르게 온 도가 안정됨을 확인 하였다.
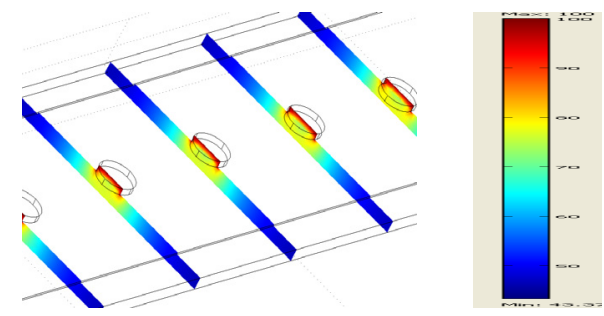

(A) COB Type
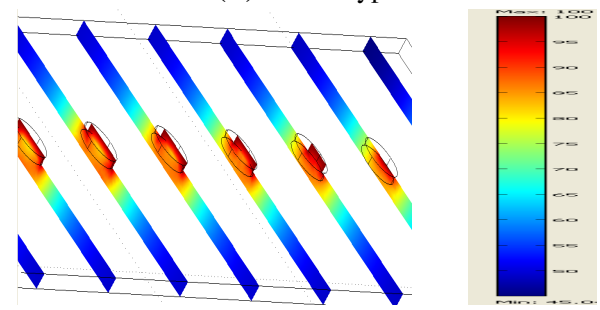

(B) $\mathrm{COH}$ Type

[그림 5] LED Module 단면 열 해석(LED Point)

[Fig. 5] Thermal Analysis of the Cross-section LED Module(LED Point)

그림 5의 (A), (B)는 LED Module(LED Point)의 단면 열 해석으로 LED Point의 온도분포이며, (A) COB Type은 단면 Max. 온도가 $100^{\circ} \mathrm{C}$ 이며, Min. 온도는 약 $43{ }^{\circ} \mathrm{C}$ 까지 온도변화를 확인 하였다. (B) COH Type은 단면 Max. 온
도가 $100^{\circ} \mathrm{C}$ 이며, Min. 온도는 약 $45^{\circ} \mathrm{C}$ 까지 온도가 분포 하였으며, LED Point에서 보다 COH Type의 방열판에서 보다 많은 열을 흡수하여 온도 차트에 보이는 것과 같이 Max. 온도에서 Min. 온도까지 COB Type 보다 빠르게 온 도가 안정됨을 확인 하였다. 하지만 $\mathrm{COH}$ Type의 LED Point에서 순간적인 고열을 시뮬레이션에서는 방열판이 흡수하여, 온도의 안정화를 이루지만 실 제작 하였을 경 우, 열에 약한 LED가 효율이 낮아질 우려가 있어 LED Module의 신뢰성 실험이 요구 되었다.

\subsection{LED Module 시뮬레이션 결과 분석}

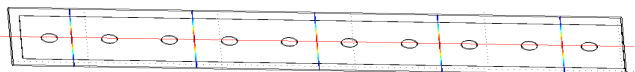

(A) Heat-sink Cross

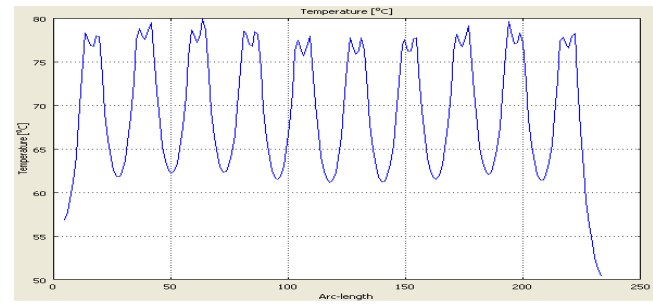

(B) 온도특성곡선

[그림 6] COB Type 방열판 온도분포

[Fig. 6] COB Type the Temperature Distribution of the Heat-sink

그림 6은 LED Module의 (A) 방열판을 통과하는 가상 선을 생성하여 그 온도변화를 확인하는 (B)온도특성곡선 이다. 시뮬레이션 결과 방열판을 통과하는 위치에 따라 $\operatorname{Max}$. 약 $78^{\circ} \mathrm{C} \sim \operatorname{Min}$. 약 $62^{\circ} \mathrm{C}$ 에서 온도가 안정이 됨을 확인하였다.

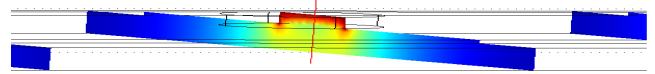

(A) LED Cross

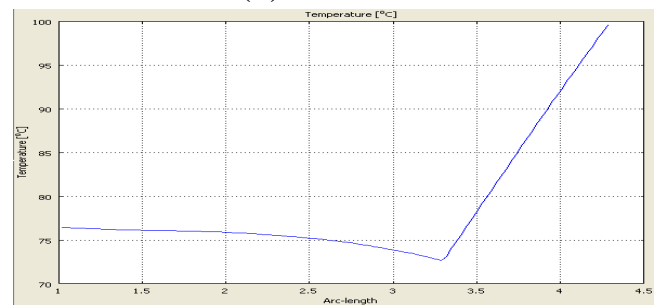

(B) 온도특성곡선

[그림 7] COB Type LED Point 온도분포

[Fig. 7] LED Point Temperature Distribution of COB Type 
그림 7은 LED Module의 (A) LED Point를 관통하는 가상선을 생성하여 (B) 온도특성곡선을 확인 한 결과로 Max. 약 $100^{\circ} \mathrm{C} \sim \operatorname{Min}$. 약 $77^{\circ} \mathrm{C}$ 에서 온도가 안정이 됨을 확인하였다.

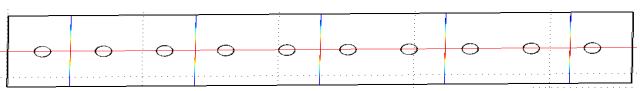

(A) Heat-sink Cross

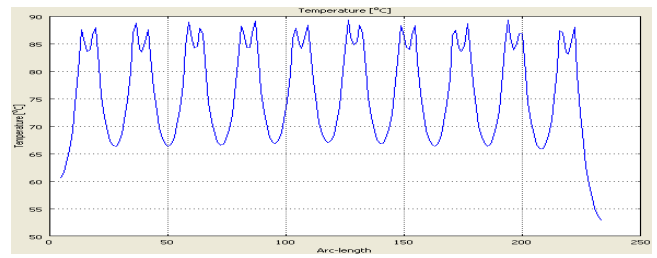

(B) 온도특성곡선

[그림 8] $\mathrm{COH}$ Type 방열판 온도분포

[Fig. 8] LED Point Temperature Distribution of COH Type

그림 8은 LED Module의 시뮬레이션 결과 방열판을 통과하는 위치에 따라 Max. 약 $88^{\circ} \mathrm{C} \sim \operatorname{Min}$. 약 $67^{\circ} \mathrm{C}$ 에 서 온도가 안정이 됨을 확인하였으며, $\mathrm{COB}$ Type과 비교 하여 Max. 온도는 약 $10^{\circ} \mathrm{C}$ 차이가 나지만, Min. 온도에서 약 $5^{\circ} \mathrm{C}$ 정도로 격차가 감소함을 확인하였다.

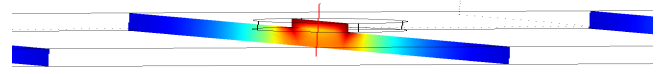

(A) LED Cross

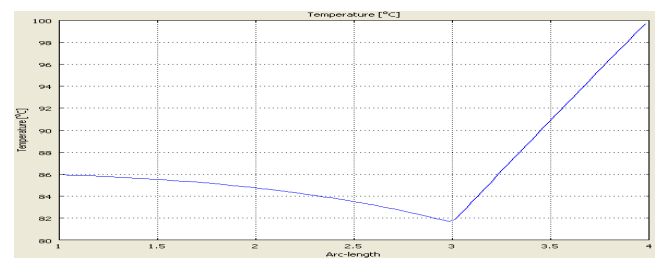

(B) 온도특성곡선

[그림 9] $\mathrm{COH}$ Type LED Point 온도분포

[Fig. 9] LED Point Temperature Distribution of $\mathrm{COH}$ Type

그림 9는 $\mathrm{Max}$. 약 $100^{\circ} \mathrm{C} \sim \operatorname{Min}$. 약 $86^{\circ} \mathrm{C}$ 에서 온도가 안정이 되며, $\mathrm{COB}$ Type에 비해 약 $10^{\circ} \mathrm{C}$ 온도가 높게 측 정되었다.

\section{3. 결론}

본 논문에서는 열 해석 시뮬레이션 프로그램인
COMSOL Multiphysics를 활용하여, LED Module의 제작 시, 가장 선호되는 패키지 종류인 $\mathrm{COB}$ Type과 보드를 생략한 $\mathrm{COH}$ Type의 열 해석 시뮬레이션을 진행, 분석한 결과는 다음과 같다.

1. LED Module의 시뮬레이션 결과 방열판을 통과하 는 위치에 따라 $\mathrm{COB}$ Type은 Max. 약 $78^{\circ} \mathrm{C} \sim \operatorname{Min}$. 약 $62^{\circ} \mathrm{C}, \mathrm{COH}$ Type은 Max. 약 $88^{\circ} \mathrm{C} \sim \operatorname{Min}$. 약 6 $7{ }^{\circ} \mathrm{C}$ 에서 온도가 안정이 됨을 확인하였으며, $\mathrm{COB}$ Type과 비교하여 Max. 온도는 약 $10^{\circ} \mathrm{C}$ 차이가 나 지만, Min. 온도에서 약 $5^{\circ} \mathrm{C}$ 정도로 격차가 감소함 을 확인하였다.

2. LED Module의 LED Point 온도특성곡선을 확인 한 결과 COB Type은 Max. 약 $100^{\circ} \mathrm{C} \sim \operatorname{Min}$. 약 $77^{\circ} \mathrm{C}$, $\mathrm{COH}$ Type은 Max. 약 $100^{\circ} \mathrm{C} \sim \operatorname{Min}$. 약 $86^{\circ} \mathrm{C}$ 온도 가 안정이 됨을 확인하였으며, $\mathrm{COB}$ Type에 비해 $\mathrm{COH}$ Type이 약 $10^{\circ} \mathrm{C}$ 온도가 높게 측정되었다.

3. COB Type과 보드를 생략한 $\mathrm{COH}$ Type의 열 해석 시뮬레이션을 진행하여, 기존의 열 설계 시뮬레이 션에서는 단면위주의 열 해석이지만, Point 지정을 통한 열 해석을 및 실험을 하여 더욱 자세한 결과 값을 얻을 수 있었다.

4. LED Module의 제작하여, Module의 전원을 공급하 면, 시간의 흐름에 따라 온도계 측정을 통한 열 해 석을 진행하는 경우가 있다. 실제 제작을 통한 열 측정을 하면, 개발에 따른 많은 경비와 기계적 손실 에 의한 결과 값에 오류가 발생하게 된다. 본 시뮬 레이션 통한 LED Module의 Modeling 및 시뮬레이 션 열 해석 방법은 산업체의 LED Module 개발 시 경비 절감의 효과및 실제 제작을 하지 않고 시뮬레 이션을 통한 결과 값의 오차 범위를 줄일 수 있다.

5. $\mathrm{COH}$ Type의 LED Point에서 순간적인 고열을 시뮬 레이션에서는 방열판이 흡수하여, 온도의 안정화를 이루지만 실 제작 하였을 경우, 열에 약한 LED가 효율이 낮아질 우려가 있어 LED Module의 신뢰성 실험이 요구 되었다.

\section{References}

[1] Ik-Soo, Eo, "Analyze on Heat-sink of 20Watt Class LED Lamp using COMSOL", Korea Journal of University-Industry Technology, Vol. 10, No. 7, pp. 1484-1488, 2009.

[2] Chi-Won, Ok, "A Study on Optimization of the Heat Sink for Reliability Improvement of High Power 
Light Emitting Diode",Proceedings of a Master's Degree in Chonbuk National University, 2006. February.

[3] Soon-Ho, Hwang, "Study on Thermal Design of LED Lights", Proceedings of a Master's Degree in Kongju National University, 2011. February.

[4] Keum-Yeon, Choi, Ik-Soo, Eo, "LED Sensitive Light System Development by Brain-wave", Korea Journal of University-Industry Technology, Vol. 11, No. 1, pp. 61-66, 2010. January.

[5] ACETec Co. Ltd, "Thermoelectric Element Training", ACETec Co. Ltd, pp. 4-7, 2007. March.

\section{최 금 연(Keum-Yeon Choi)}

[정회원]

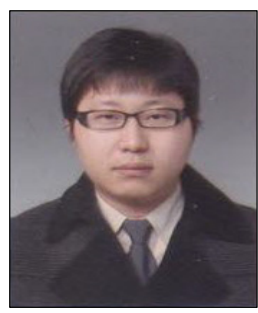

- 2008년 2월 : 호남대학교 전기공 학과 졸업(공학사)

- 2010년 2월 : 호남대학교 전기전 자대학원 졸업(공학석사)

- 2010년 3월 현재 : 호남대학교 전기전자대학원 재학(박사과정)

<관심분야>

광학 및 방열설계

\section{어 익 수(Ik-Soo Eo)}

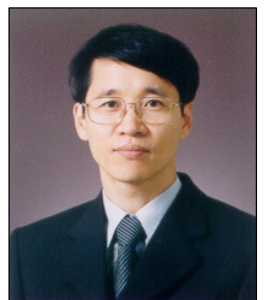

- 1986년 2월 : 서울산업대학교 전 기공학과(공학사)

- 1996년 2월 : 한양대학교 전기공 학과(공학석사)

- 2008년 2월 : 서울벤쳐정보대학 원 전기공학과(공학박사)

- 1995년 5월 : 건축전기기술사, 전기안전기술사

- 1998년 2월 현재 : 호남대학교 전기공학과 부교수

<관심분야>

전기설비, LED조명 설계, Heat-sink 